\title{
Testing for Unit Roots and Structural Breaks: Evidence from Selected ASEAN Macroeconomic Time Series
}

\author{
Tan Yan Ling, Abu Hassan Shaari Mohd Nor, Nur Adilah Saud, and Zailati Ahmad
}

\begin{abstract}
The purpose of this study is to carry out a comprehensive examination of the unit root hypothesis and structural breaks in ASEAN macroeconomic time series from 1960 to 2010 using endogenous break ADF-type unit root tests. Once allowance is considered for structural breaks, the number of rejections of a unit root null is relatively higher than without breaks. The difference between $\mathrm{ZA}$ and LP models, is that $\mathrm{ZA}$ shows that US Dollar terms denomination series are more favorable of trend-stationary processes, whereas the series under local currency terms tend to reject the null hypothesis of a unit root in LP models. Moreover, the break points are closely associated with global economic events such as the first and second oil shocks in 1973-1975 and 1979-1980, respectively, the commodity crisis (1985-1986) and the Asian financial crisis (1997-1998). The policy authorities may use the historical information to forecast future movements in macroeconomic time series. Lastly, our findings also shed light on the importance of considering exchange rate fluctuations in the process of trend-stationary and unit root.
\end{abstract}

Index Terms-Unit root, structural break, macroeconomic time series, ASEAN.

\section{INTRODUCTION}

The studies on the macroeconomic time series properties have received a considerable interest in business cycle research during the 1970s. One of the most arguable and considerable topics among economists is whether macroeconomic time series can be characterized as a random walk (unit root) or trend-stationary. From the conventional view of the business cycles suggest that business cycles are temporary movements in economic variables, such as real GNP. The impact of shock on output growth will vanish eventually and output will return to its trend rate of growth. In this case, growth of output is characterized as trend-stationary.

This traditional economist point, however, contrary to what empirical findings by [1] suggested. This new strand of research have challenged the basic beliefs of traditional views in treating economic time series as temporary fluctuations around a deterministic trend function as opposed to the permanent changes reflected in the trend. Reference [1]

Manuscript received May 20, 2013; revised July 19, 2013. This work was supported by the Malaysian Ministry of Higher Education (MOHE) under Fundamental Research Grant Scheme (FRGS) Phase 2/2010.

Tan Yan Ling, Nur Adilah Saud, and Zailati Ahmad are with Faculty of Business and Management, Universiti Teknologi MARA Johor Branch, Segamat, Johor, Malaysia (e-mail: tyling118@yahoo.com, kakak510@yahoo.com,zaila856@johor.uitm.edu.my).

Abu Hassan Shaari Mohd Nor is with Faculty of Economics and Management, Universiti Kebangsaan Malaysia, Bangi, Selangor, Malaysia (e-mail: ahassan@ukm.my). have finalized an important finding in US data which the hypothesis that GDP follows a random walk cannot be rejected. Then, they argue that most of the changes in GDP are permanent, indicating that there is no tendency for output growth to revert to its underlying trend following a shock. Hence, output will persist in every future period and GNP is said to be random walk.

In this study, we focus the issues in several aspects. Firstly, most studies have focused on the unit root hypothesis and structural breaks in OECD countries [2]-[8], emerging markets [9], developed and developing countries [10], G7 [11]; US [1], [12]-[18], North American countries [19], UK [20], Australia [21], Brazil [22], Papua New Guinea (PNG) [23] and China [24]. However, it is rather surprising that there are no serious attempts and yet no comprehensive studies have been made on ASEAN macroeconomic time series. Hence, an in-depth analysis of statistical properties in this context of is needed. The second issue is related to the ignorance of structural breaks. Many previous empirical studies do not consider structural breaks in the study. One noticeable feature is that most of the financial and macroeconomics time series with a long-span historical time are subject to the existence of structural breaks [3]. If the unit root tests do not account for the existence of structural breaks that arise from any economic events are wrongly specified [7], they tend to produce inaccurate inference [9] and might lead to bias and spurious rejection. Furthermore, structural breaks are normally associated with anomalous events. Most noteworthy events in ASEAN are the first oil crisis in $1973-75$, the second oil crisis in 1979-80, the commodity crisis in 1985-86, the Asian financial crisis in1997-98 and the some recent events including the SARS epidemic in 2003, the energy shock in 2005 and the most recent global financial crisis in 2008-09. These major shocks were particularly severe on macroeconomic condition, and the overall ASEAN economy recorded a sharp contraction and fluctuation over these periods. Therefore, the behavior of ASEAN macroeconomic time series may react differently due to the effects of a number of financial and economic events occurred over the period of the study. The third issue is about the statistical properties of macroeconomic variables under US Dollars and local currencies denomination. Most of the existing studies focused on rate variables: inflation rate [3], [4], [8], [25], unemployment rate [2], [7], [19], real interest rate [21], stock prices [9]-[11], energy prices [5] and other macroeconomic variables series [12]-[14], [23], [26], [27]. These studies consider only variables either US Dollar denomination or local-currency denomination, while no attempt is being focused on both US Dollar and local-currency denominated macroeconomic time series 
except [9] on stock prices denominated in both currencies terms. According to [9], it is important to consider exchange rate fluctuations in the study as exchange rates are subject to structural breaks and may be characterized as trend-stationary.

Therefore, this study begins with the general objective of examining the unit root hypothesis and structural breaks of various macroeconomic time series in selected ASEAN countries over the last 50 years. More specifically, this study aims at giving a comprehensive and systematic examination on macroeconomic variables denominated under US Dollar and under local currency terms using different endogenous structural break ADF-type unit root tests. Lastly, the timing of possible structural breaks can be determined endogenously.

\section{DATA}

We use the natural logarithm (LN) of macroeconomic time series for five (5) selected ASEAN countries namely Indonesia (IDN), Malaysia (MYS), Philippines (PHL), Singapore (SGP) and Thailand (THA) as displayed in Table I. Data are annual, generally covers the time period from 1960 (1967 and 1970) and end in 2010. The time period is different among ASEAN countries depending on data availability. In addition, this chosen period allows for the possibility of major structural changes. The sample data are obtained from the International Monetary Fund's (IMF) International Financial Statistics (IFS). The 10 macroeconomic time series are separated into US Dollars-denominated and local currencies-denominated variables.

TABLE I: VARIABLES DESCRIPTION

\begin{tabular}{cll}
\hline & Variables (Millions) & \\
\hline & Nominal gross domestic product (Local & \\
1 & Currency) & LNGDP \\
2 & $\begin{array}{l}\text { Nominal gross domestic product (US dollars) } \\
\text { Nominal Public Final Consumption }\end{array}$ & LNGDPUS \\
3 & $\begin{array}{l}\text { Expenditure (Local Currency) } \\
\text { Nominal Public Final Consumption }\end{array}$ & LNPCE \\
4 & $\begin{array}{l}\text { Expenditure (US dollars) } \\
\text { Nominal Private Final Consumption }\end{array}$ & LNPCEUS \\
5 & $\begin{array}{l}\text { Expenditure (Local Currency) } \\
\text { Nominal Private Final Consumption }\end{array}$ & LNPICE \\
7 & Expenditure (US dollars) & LNPICEUS \\
8 & Exports of goods (Local Currency) & LX \\
9 & Imports of goods (Local Currency) & LXUS \\
10 & Imports of goods (US dollars) & LM \\
\hline & & LMUS \\
\hline
\end{tabular}

\section{Methodology}

Various methodologies have been widely applied to examine the unit root hypothesis and structural breaks. In this study, we firstly discuss unit root test without structural breaks or Augmented Dickey-Fuller (ADF) tests, it is then followed by endogenous break ADF-type test with a single endogenous (unknown) break and two endogenous breaks.

\section{A. Unit Root Tests without Structural Break}

In most of the empirical literature the Augmented Dickey-Fuller (hereafter ADF) tests are the commonly used methods for detecting the presence of a unit root. The ADF test [28], [29] is an augmented version of the Dickey-Fuller (hereafter DF) test by adding the lagged values of the dependent variable. The ADF test involves regressing on the first difference of a variable on a constant, a linear deterministic trend, a lagged first difference and k-lagged first differences. It can be expressed as follows:

$$
\Delta Y_{t}=\mu+\alpha Y_{t-1}+\beta t+\sum_{j=1}^{k} c_{j} \Delta Y_{t-j}+\varepsilon_{t}
$$

where $\Delta$ is the first difference operator, $Y_{t}$ is the macroeconomic time series, $\varepsilon_{t}$ is a white noise disturbance with variance $\sigma^{2}, \mathrm{t}=1, \ldots, \mathrm{T}$ is an index of time, $\Delta Y_{t-j}$ is the lagged first differences to correct for serial autocorrelation in the errors. The optimal lag length $(k)$ is selected using $t$-sig approach as proposed by [30] with $k$-max $=8$. This method is also further suggested by [31] that the $t$-sig approach gives test statistics with better properties in terms of stable size and high power than when $k$ is selected using information-based criteria such as the Akaike information criterion (AIC) and Schwarz information criterion (SIC). One model is chosen with the lag length if the last lag of the first difference is significant at the 10 percent level or lower [31]. This method has been widely used in empirical studies [24], [32]. The null hypothesis of a unit root is tested against the alternative that the process is stationary. In this case, failing to reject the null hypothesis indicates that the macroeconomic time series contain unit root; whereas the macroeconomic time series is said to be stationary when null hypothesis is rejected.

\section{B. Unit root Tests with Endogenous Structural Break Zivot and Andrews (1992)}

A large body of empirical studies have evidenced empirically that most macroeconomic time series have a unit root. Reference [1] found evidence in favor of unit root hypothesis, suggesting that 13 out of 14 long-run annual macroeconomic time series contain unit root. The ADF tests did not encounter for possible structural breaks in estimation of unit roots. However, [15] proposed the importance to consider a potential break in trend. Reference [15] finalized that the ADF tests tend to bias the conclusion towards a unit root if there is a one-time existence in the mean of the series (structural break). The problem occurs when there is a break in the series; this shock may have a permanent effect on the series. This condition becomes much worse if the series is stationary, such shock will initially have a transitory effect, and however, the existence of such a structural break will make the shock have a permanent effect. This may indirectly lead towards the non-rejection of a unit root. Reference [15]'s assumption of the structural break is exogenously determined has received some criticism in the literature. This is because selecting an exogenous structural break point will lead to over rejection of the unit root hypothesis. Thus, a number of studies allowed the structural break to be endogenous (unknown) in the series [16]-[17], [33]. They have shown that the inclusion of an unknown break in the series will reduce the bias in the unit root tests. Reference [16] extended [15]'s idea and introduced an endogenous 
break in the model. This model is also called as a sequential trend break model. The differences are [15]'s method is a predetermined break, while [16] method is an estimated break. Follow [15]'s methodology, the crash dummy, $D(T B)$ is not included in [16] models. These models are model A, model $\mathrm{B}$ and model $\mathrm{C}$ as follows:

Model A and model B allow for a change in the intercept and in the slope, respectively, while model $\mathrm{C}$ allows for a change in both intercept and slope.

- Model A:

$$
\Delta Y_{t}=\mu+\alpha Y_{t-1}+\beta t+\theta D U_{t}+\sum_{j=1}^{k} c_{j} \Delta Y_{t-j}+\varepsilon_{t}
$$

- Model B:

$$
\Delta Y_{t}=\mu+\alpha Y_{t-1}+\beta t+\gamma D T_{t}^{*}+\sum_{j=1}^{k} c_{j} \Delta Y_{t-j}+\varepsilon_{t}
$$

- Model C:

$$
\Delta Y_{t}=\mu+\alpha Y_{t-1}+\beta t+\theta D U_{t}+\gamma D T_{t}^{*}+\sum_{j=1}^{k} c_{j} \Delta Y_{t-j}+\varepsilon_{t}
$$

where the intercept dummy $D U_{t}=1$ if $t>T_{B}$ and zero otherwise ( $T_{B}$ is the time break), the slope dummy $D T_{t}^{*}=t-T_{B}$ if $t>T_{B}$ and zero otherwise.

In equations (2)-(4), the null hypothesis of a unit root against the alternative hypothesis that the series is stationary is tested. According to [16] (hereafter ZA), every point is considered as a potential break point $\left(T_{B}\right)$ and regression will run for every possible break point sequentially. Among all the possible break points, a break point $\left(T_{B}\right)$ is selected when the absolute value of $t$-statistic from the ADF test is minimized. In addition, the break point can also be searched over the range of sample $(0.15 T-0.85 T)$. By considering a break point endogenously, ZA find less conclusive evidence against unit roots than [15]'s tests.

\section{Lumsdaine and Papell (1997)}

Reference [18] (hereafter LP) extended ZA's framework by incorporating two endogenous structural breaks in the model. This is because allowing for two possible structural breaks are more powerful than allowing for a single structural break. The modification of models can be expressed as models AA, CA and CC, respectively.

- Model AA:

$\Delta Y_{t}=\mu+\alpha Y_{t-1}+\beta t+\theta D U 1_{t}+\varpi D U 2_{t}+\sum_{j=1}^{k} c_{j} \Delta Y_{t-j}+\varepsilon_{t}(5)$

- Model CA:

$\Delta Y_{t}=\mu+\alpha Y_{t-1}+\beta t+\theta D U 1_{t}+\gamma D T 1_{t}+\varpi D U 2_{t}+\sum_{j=1}^{k} c_{j} \Delta Y_{t-j}+\varepsilon_{t}$
$\Delta Y_{t}=\mu+\alpha Y_{t-1}+\beta t+\theta D U 1_{t}+\gamma D T 1_{t}+\varpi D U 2_{t}+\psi D T 2_{t}+\sum_{j=1}^{k} c_{j} \Delta Y_{t-j}+\varepsilon_{t}$

where

- $D U 1_{t}=1 \quad$ if $t>T_{B 1}$ and zero otherwise

- $D U 2_{t}=1$ if $t>T_{B 2}$ and zero otherwise

- $D T 1_{t}=t-T_{B 1}$ if $t>T_{B 1}$ and zero otherwise

- $D T 2_{t}=t-T_{B 2}$ if $t>T_{B 2}$ and zero otherwise

$D U 1_{t}$ and $D U 2_{t}$ are two dummy variables that allow structural changes in the intercept at $T_{B 1}$ and $T_{B 2}$, respectively. While $D T 1_{t}$ and $D T 1_{t}$ are two dummy variables account shifts in the trend variable at $T_{B 1}$ and $T_{B 2}$, respectively. Model AA allows for two structural breaks in the intercept, while model $\mathrm{CC}$ allows for two structural breaks in the intercept and the slope. Model CA allows for the first breaks in the both intercepts and second break in the slope only. The possible break dates, $T_{B 1}$ and $T_{B 2}$ are selected based on the minimum value of $t$-statistic. They re-examine the Nelson-Plosser data and reject the null of a unit root for seven out of 13 macroeconomic series at the 5\% and two additional macroeconomic series at the $10 \%$ level of significance. In brief, they find more evidence in rejecting the unit root hypothesis than ZA, but less evidence than [15]. As a conclusion, all methodologies discussed in the above are based on the univariate unit root tests and structural breaks.

\section{EMPIRICAL RESULTS}

Table II presents the results for the ADF tests on 10 macroeconomic series in ASEAN countries. The ADF tests fail to reject the unit root-null for most macroeconomic time series in Indonesia and Philippines. Even worse is the result for Malaysia, Singapore and Thailand where none of the macroeconomic variables could reject the null hypothesis of a unit root. The overall ADF results show more supportive evidence of random walk regardless of whether including a time trend or without a time trend in the series. These findings suggest that shocks to the macroeconomic variables have a permanent effect. Nevertheless, the ADF tests could lead to misspecifications and misinterpretations if potential structural breaks are ignored. We thus further include an endogenous structural break in ADF-type unit root tests. In this study, we follow [9] in which one model is chosen if the model gives the most negative results in the unit root hypothesis or the model provides the most significant test statistic on $\alpha=0$. The most negative results for endogenous break ADF-type unit root tests are reported in Tables III - IV, respectively.

When the ADF-type tests are expanded by allowing for endogenous breaks in trend along the lines of ZA and others [17], [18], it can be concluded that the unit root null is more frequently rejected. We find stronger rejections of unit root with two endogenous breaks than the results in single 
endogenous break. More specifically, after controlling one-break and two-break endogenously, the evidence reveals that most macroeconomic time series are trend-stationary in Indonesia. However, less evidence is found in supporting trend-stationary processes in the remaining countries.

\begin{tabular}{|c|c|c|c|c|c|c|c|}
\hline & \multirow[b]{2}{*}{ Variables } & \multicolumn{6}{|c|}{ IDN } \\
\hline & & Trend & & $\mathbf{k}$ & No Trend & & $\mathbf{k}$ \\
\hline 1 & $\begin{array}{l}\text { LNGDP } \\
\text {. }\end{array}$ & -20.5406 & **** & 5 & -0.7528 & & 7 \\
\hline 2 & LNGDPUS & -2.1714 & & 0 & -1.5381 & & 0 \\
\hline 3 & LNPCE & -1.5814 & & 7 & -0.0867 & & 7 \\
\hline 4 & LNPCEUS & -2.1401 & & 0 & -1.7489 & & 0 \\
\hline 5 & LNPICE & -17.8134 & $* * *$ & 5 & -3.1415 & $* *$ & 5 \\
\hline 6 & LNPICEUS & -2.2462 & & 0 & -1.1353 & & 0 \\
\hline 7 & LX & -2.1207 & & 0 & -2.4079 & & 0 \\
\hline 8 & LXUS & -2.2788 & & 3 & -1.2476 & & 3 \\
\hline 9 & LM & -2.221 & & 8 & -2.7895 & * & 6 \\
\hline \multirow[t]{3}{*}{10} & LMUS & -2.4457 & & 3 & -0.5844 & & 0 \\
\hline & & \multicolumn{6}{|c|}{ MYS } \\
\hline & Variables & Trend & & $\mathbf{k}$ & No Trend & & $\mathbf{k}$ \\
\hline 1 & $\begin{array}{l}\text { LNGDP } \\
\text { L }\end{array}$ & -2.1986 & & 3 & -0.4705 & & 0 \\
\hline 2 & LNGDPUS & -1.9424 & & 1 & -0.8229 & & 0 \\
\hline 3 & LNPCE & -2.0982 & & 0 & -1.3357 & & 0 \\
\hline 4 & LNPCEUS & -1.7512 & & 0 & -1.4735 & & 0 \\
\hline 5 & LNPICE & -2.74 & & 1 & -0.1311 & & 0 \\
\hline 6 & LNPICEUS & -2.2591 & & 1 & -0.6958 & & 1 \\
\hline 7 & $\mathrm{LX}$ & -3.0002 & & 0 & 0.1559 & & 0 \\
\hline 8 & LXUS & -2.4448 & & 5 & -0.1631 & & 0 \\
\hline 9 & LM & -2.3792 & & 6 & -0.1079 & & 0 \\
\hline \multirow[t]{3}{*}{10} & LMUS & -2.3588 & & 1 & -0.4066 & & 0 \\
\hline & & \multicolumn{6}{|c|}{ PHL } \\
\hline & Variables & Trend & & $\mathbf{k}$ & No Trend & & $\mathbf{k}$ \\
\hline 1 & LNGDP & -0.8177 & & 5 & -1.7578 & & 0 \\
\hline 2 & LNGDPUS & -3.1793 & & 8 & 0.2212 & & 0 \\
\hline 3 & LNPCE & -0.7473 & & 1 & -1.3896 & & 1 \\
\hline 4 & LNPCEUS & -4.3522 & $* * *$ & 8 & -0.0455 & & 0 \\
\hline 5 & LNPICE & -1.2749 & & 7 & -1.5875 & & 5 \\
\hline 6 & LNPICEUS & -3.1879 & & 8 & 0.3585 & & 0 \\
\hline 7 & LX & -2.1225 & & 4 & -1.3472 & & 0 \\
\hline 8 & LXUS & -3.8693 & $* *$ & 8 & -0.4337 & & 0 \\
\hline 9 & LM & -0.0431 & & 0 & -2.0930 & & 0 \\
\hline \multirow[t]{3}{*}{10} & LMUS & -3.02 & & 7 & -0.8202 & & 0 \\
\hline & & \multicolumn{6}{|c|}{ SGP } \\
\hline & Variables & Trend & & $\mathbf{k}$ & No Trend & & $\mathbf{k}$ \\
\hline 1 & LNGDP & -1.0296 & & 1 & -2.9418 & & 8 \\
\hline 2 & LNGDPUS & -1.8227 & & 1 & -2.1337 & & 8 \\
\hline 3 & LNPCE & -0.6315 & & 0 & -2.3587 & & 0 \\
\hline 4 & LNPCEUS & -0.6338 & & 0 & -1.8813 & & 0 \\
\hline 5 & LNPICE & -1.1424 & & 1 & -2.4573 & & 4 \\
\hline 6 & LNPICEUS & -1.9693 & & 1 & -0.7276 & & 1 \\
\hline 7 & LX & -1.5411 & & 0 & -0.3631 & & 0 \\
\hline 8 & LXUS & -2.0028 & & 1 & -0.5441 & & 1 \\
\hline 9 & LM & -1.1007 & & 0 & -0.7869 & & 0 \\
\hline \multirow[t]{3}{*}{10} & LMUS & -1.7012 & & 1 & -0.8216 & & 1 \\
\hline & & \multicolumn{6}{|c|}{ THA } \\
\hline & Variables & Trend & & $\mathbf{k}$ & No Trend & & $\mathbf{k}$ \\
\hline 1 & LNGDP & -0.4557 & & 5 & -1.8628 & & 5 \\
\hline 2 & LNGDPUS & -2.2308 & & 3 & -1.1588 & & 3 \\
\hline 3 & LNPCE & -0.0371 & & 7 & -2.5926 & & 7 \\
\hline 4 & LNPCEUS & -2.3948 & & 3 & -2.2691 & & 7 \\
\hline 5 & LNPICE & -0.6116 & & 1 & -1.6639 & & 1 \\
\hline 6 & LNPICEUS & -2.158 & & 3 & -1.1763 & & 1 \\
\hline 7 & LX & -1.9181 & & 7 & -0.2576 & & 0 \\
\hline 8 & LXUS & -2.2635 & & 1 & -0.2951 & & 0 \\
\hline 9 & LM & -2.0066 & & 1 & -0.8493 & & 0 \\
\hline 10 & LMUS & -2.4347 & & 1 & -0.8398 & & 0 \\
\hline
\end{tabular}

Notes:
The optimal lag length for the ADF tests is selected using $t$-sig approach as suggested by[31], with the maximum lag set to 8 . The ADF tests are based on the null hypothesis of unit root. $* * *, * *$, and $*$ indicate significant at 1 percent, 5 percent, and 10 percent level respectively.
TABLE III: RESULTS FOR ZIVOT AND ANDREWS (1992)

\begin{tabular}{llcccrl}
\hline & & \multicolumn{6}{c}{ IDN } \\
\cline { 3 - 7 } & Variables & Model & $\mathbf{k}$ & TB & t-statistic & \\
\hline 1 & LNGDP & $\mathrm{A}$ & 5 & 1979 & -23.6064 & $* * *$ \\
2 & LNGDPUS & $\mathrm{A}$ & 0 & 1973 & -3.4619 & \\
3 & LNPCE & $\mathrm{B}$ & 8 & 1996 & -3.5639 & \\
4 & LNPCEUS & $\mathrm{C}$ & 0 & 1997 & -2.7091 & \\
5 & LNPICE & $\mathrm{B}$ & 4 & 2003 & -8.0055 & $* * *$ \\
6 & LNPICEUS & $\mathrm{A}$ & 8 & 1998 & -4.2377 & \\
7 & LX & $\mathrm{B}$ & 0 & 1975 & -3.5553 & \\
8 & LXUS & $\mathrm{A}$ & 3 & 1973 & -5.7523 & $* * *$ \\
9 & LM & $\mathrm{C}$ & 0 & 1984 & -4.4900 & \\
10 & LMUS & $\mathrm{A}$ & 1 & 1973 & -4.7175 & $*$ \\
\hline
\end{tabular}

\begin{tabular}{llcccrl}
\hline & & \multicolumn{5}{c}{ MYS } \\
\cline { 3 - 7 } & Variables & Model & $\mathbf{k}$ & TB & t-statistic \\
\hline 1 & LNGDP & $\mathrm{A}$ & 0 & 1976 & -3.7866 & \\
2 & LNGDPUS & $\mathrm{A}$ & 1 & 1973 & -4.1682 & \\
3 & LNPCE & $\mathrm{C}$ & 2 & 1977 & -4.8551 & $*$ \\
4 & LNPCEUS & $\mathrm{A}$ & 0 & 1972 & -3.4864 & \\
5 & LNPICE & $\mathrm{C}$ & 1 & 1976 & -4.1799 & \\
6 & LNPICEUS & $\mathrm{A}$ & 1 & 1997 & -4.0936 & \\
7 & LX & $\mathrm{B}$ & 0 & 2001 & -3.8542 & \\
8 & LXUS & $\mathrm{A}$ & 0 & 1973 & -4.2770 & \\
9 & LM & $\mathrm{C}$ & 0 & 1989 & -3.1923 \\
10 & LMUS & $\mathrm{B}$ & 1 & 1995 & -3.5234 & \\
\hline
\end{tabular}

\begin{tabular}{clccccc}
\hline & & \multicolumn{5}{c}{ PHL } \\
\cline { 3 - 7 } & Variables & Model & $\mathbf{k}$ & TB & t-statistic & \\
\hline 1 & LNGDP & $\mathrm{C}$ & 0 & 1984 & -3.5512 & \\
2 & LNGDPUS & $\mathrm{C}$ & 1 & 1983 & -4.7208 & \\
3 & LNPCE & $\mathrm{B}$ & 1 & 1998 & -4.0383 & \\
4 & LNPCEUS & $\mathrm{C}$ & 8 & 1978 & -5.9318 & $* * *$ \\
5 & LNPICE & $\mathrm{C}$ & 0 & 1984 & -4.4035 & \\
6 & LNPICEUS & $\mathrm{C}$ & 8 & 1990 & -6.0988 & $* * *$ \\
7 & LX & $\mathrm{C}$ & 0 & 1998 & -4.7144 & \\
8 & LXUS & $\mathrm{C}$ & 8 & 1985 & -3.9822 & \\
9 & LM & $\mathrm{B}$ & 0 & 2001 & -3.2676 & \\
10 & LMUS & $\mathrm{A}$ & 1 & 1974 & -4.2621 & \\
\hline
\end{tabular}

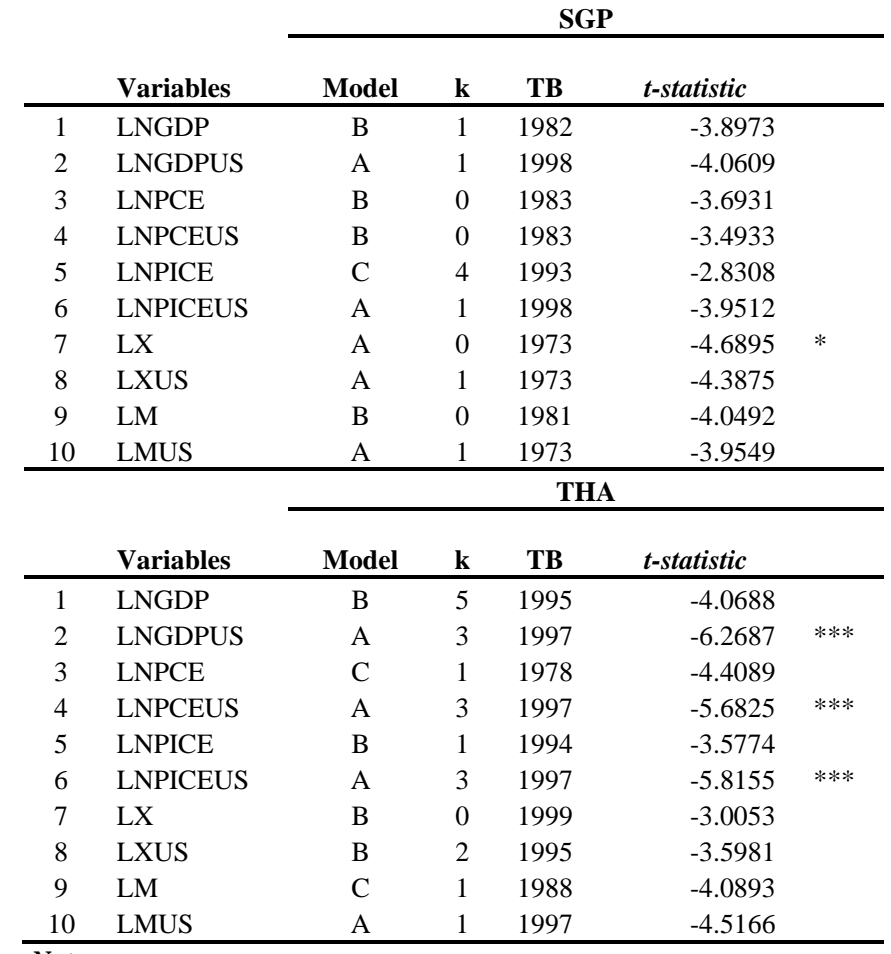

Notes:

The optimal lag length is selected using $t$-sig approach as suggested by [31], with the maximum lag set to 8 . The ZA tests are based on the null hypothesis of unit root. $* * *, * *$, and $*$ indicate significant at 1 percent, 5 percent, and 10 percent level respectively. The 1 percent, 5 percent and 10 percent asymptotic critical values for Model A: $-5.34,-4.80$ and -4.58 ; Model B: $-4.93,-4.42$ and -4.11 ; Model C: $-5.57,-5.08$ and -4.82 . 
TABLE IV: RESULTS FOR LUMSDAINE AND PAPELL (1997)

\begin{tabular}{|c|c|c|c|c|c|c|c|}
\hline & \multirow[b]{2}{*}{ Variables } & \multicolumn{6}{|c|}{ IDN } \\
\hline & & Model & $\mathbf{k}$ & TB1 & TB2 & $t$-statistic & \\
\hline 1 & LNGDP & AA & 6 & 1979 & 1998 & -8.1227 & $* * *$ \\
\hline 2 & LNGDPUS & $\mathrm{CC}$ & 0 & 1983 & 1998 & -7.1972 & $* *$ \\
\hline 3 & LNPCE & $\mathrm{CC}$ & 6 & 1981 & 1999 & -7.7450 & $* * *$ \\
\hline 4 & LNPCEUS & $\mathrm{CC}$ & 4 & 1983 & 1998 & -7.6939 & $* * *$ \\
\hline 5 & LNPICE & $\mathrm{CC}$ & 5 & 1985 & 1998 & -27.3096 & $* * *$ \\
\hline 6 & LNPICEUS & $\mathrm{CC}$ & 0 & 1983 & 1998 & -5.8559 & \\
\hline 7 & LX & $\mathrm{CC}$ & 0 & 1978 & 1997 & -6.2627 & \\
\hline 8 & LXUS & CA & 0 & 1973 & 1985 & -6.9263 & $* * *$ \\
\hline 9 & LM & $\mathrm{CC}$ & 5 & 1982 & 1997 & -7.6947 & $* * *$ \\
\hline \multirow[t]{3}{*}{10} & LMUS & $\mathrm{CA}$ & 3 & 1973 & 1998 & -5.1311 & \\
\hline & & \multicolumn{6}{|c|}{ MYS } \\
\hline & Variables & Model & $\mathbf{k}$ & TB1 & TB2 & $t$-statistic & \\
\hline 1 & LNGDP & AA & 1 & 1976 & 1993 & -4.6193 & \\
\hline 2 & LNGDPUS & CA & 5 & 1978 & 1998 & -6.2392 & \\
\hline 3 & LNPCE & $\mathrm{CC}$ & 5 & 1980 & 1998 & -6.8964 & $* *$ \\
\hline 4 & LNPCEUS & $\mathrm{CC}$ & 2 & 1977 & 1998 & -5.9981 & \\
\hline 5 & LNPICE & AA & 3 & 1978 & 2001 & -5.1257 & \\
\hline 6 & LNPICEUS & CA & 5 & 1978 & 1998 & -6.0210 & \\
\hline 7 & LX & AA & 0 & 1976 & 1989 & -4.5137 & \\
\hline 8 & LXUS & $\mathrm{CC}$ & 6 & 1973 & 1995 & -5.3271 & \\
\hline 9 & LM & $\mathrm{CC}$ & 5 & 1986 & 1994 & -4.2189 & \\
\hline \multirow[t]{3}{*}{10} & LMUS & $\mathrm{CC}$ & 4 & 1978 & 1994 & -4.7588 & \\
\hline & & \multicolumn{6}{|c|}{ PHL } \\
\hline & Variables & Model & $\mathbf{k}$ & TB1 & TB2 & $t$-statistic & \\
\hline 1 & LNGDP & CA & 4 & 1974 & 1984 & -5.7169 & \\
\hline 2 & LNGDPUS & $\mathrm{CA}$ & 5 & 1973 & 1997 & -5.1685 & \\
\hline 3 & LNPCE & $\mathrm{CC}$ & 6 & 1974 & 1997 & -7.5288 & $* * *$ \\
\hline 4 & LNPCEUS & AA & 7 & 1970 & 1972 & -4.9664 & \\
\hline 5 & LNPICE & CA & 5 & 1984 & 1990 & -6.6969 & $* *$ \\
\hline 6 & LNPICEUS & CA & 5 & 1973 & 1998 & -5.9982 & \\
\hline 7 & LX & $\mathrm{CC}$ & 2 & 1970 & 1998 & -5.3847 & \\
\hline 8 & LXUS & $\mathrm{CC}$ & 0 & 1973 & 1995 & -5.3248 & \\
\hline 9 & LM & $\mathrm{CC}$ & 6 & 1985 & 2002 & -4.7080 & \\
\hline \multirow[t]{3}{*}{10} & LMUS & $\mathrm{CA}$ & 1 & 1974 & 1992 & -5.3718 & \\
\hline & & \multicolumn{6}{|c|}{ SGP } \\
\hline & Variables & Model & $\mathbf{k}$ & TB1 & TB2 & $t$-statistic & \\
\hline 1 & LNGDP & $\mathrm{CC}$ & 3 & 1980 & 1993 & -6.6129 & $*$ \\
\hline 2 & LNGDPUS & AA & 1 & 1972 & 1998 & -5.6811 & \\
\hline 3 & LNPCE & $\mathrm{CC}$ & 5 & 1982 & 2000 & -5.7318 & \\
\hline 4 & LNPCEUS & $\mathrm{CC}$ & 6 & 1982 & 1996 & -6.5137 & * \\
\hline 5 & LNPICE & $\mathrm{CC}$ & 3 & 1973 & 1993 & -6.9857 & $* *$ \\
\hline 6 & LNPICEUS & AA & 1 & 1972 & 1998 & -4.9575 & \\
\hline 7 & LX & AA & 3 & 1973 & 1978 & -5.8947 & \\
\hline 8 & LXUS & AA & 6 & 1976 & 2001 & -4.9156 & \\
\hline 9 & LM & AA & 3 & 1973 & 1978 & -5.2704 & \\
\hline \multirow[t]{3}{*}{10} & LMUS & AA & 1 & 1973 & 1998 & -5.4078 & \\
\hline & & \multicolumn{6}{|c|}{ THA } \\
\hline & Variables & Model & $\mathbf{k}$ & TB1 & TB2 & $t$-statistic & \\
\hline 1 & LNGDP & $\mathrm{CC}$ & 5 & 1978 & 1994 & -5.4039 & \\
\hline 2 & LNGDPUS & AA & 3 & 1973 & 1997 & -7.1896 & $* * *$ \\
\hline 3 & LNPCE & $\mathrm{CC}$ & 6 & 1978 & 1997 & -5.5218 & \\
\hline 4 & LNPCEUS & CA & 4 & 1978 & 1997 & -7.7375 & $* * *$ \\
\hline 5 & LNPICE & $\mathrm{CC}$ & 1 & 1973 & 1997 & -4.9782 & \\
\hline 6 & LNPICEUS & CA & 0 & 1973 & 1997 & -7.1480 & $* *$ \\
\hline 7 & LX & $\mathrm{CC}$ & 3 & 1969 & 1998 & -4.9176 & \\
\hline 8 & LXUS & AA & 7 & 1973 & 1987 & -4.6520 & \\
\hline 9 & LM & $\mathrm{CC}$ & 0 & 1974 & 1988 & -4.8461 & \\
\hline 10 & LMUS & $\mathrm{CC}$ & 1 & 1984 & 1997 & -5.1752 & \\
\hline
\end{tabular}

Notes: The optimal lag length is selected using $t$-sig approach as suggested by [31], with the maximum lag set to 8 . The LP tests are based on the null hypothesis of unit root. $* * *, * *$, and $*$ indicate significant at 1 percent, 5 percent, and 10 percent level respectively. The 1 percent, 5 percent and 10 percent asymptotic critical values for Model AA: -6.94, -6.24 and -5.96; Model CA : $-7.24,-6.65$ and -6.33; Model CC : $-7.34,-6.82$ and -6.49 .

Besides, comparing the US Dollar and local currency denomination series for both ZA and LP models, we can observe the following findings. Firstly, it is clearly concluded that Indonesia has the highest rejections of unit root null than the remaining ASEAN countries. Moreover, the unit root null for most series can be rejected in two-break models (seven out of 10 series) compared to one-break models (four out of ten variables). Among these trend-stationary macroeconomic time series, four series (two-break models) and two series (one-break models) are expressed in local currency as opposed to US Dollar denomination variables such as two-break models (three series) and one-break models (two series). Secondly, Malaysia and Thailand reveal a relatively consistent finding for LP and ZA. To be more details, we can only reject the unit root null for nominal public final consumption expenditure that denominated in local currency terms for model $\mathrm{C}$ and model $\mathrm{CC}$ at 10 percent and 5 percent level, respectively. On the one hand, Thailand has an opposite finding in which variables under US Dollar terms include nominal gross domestic product (US Dollar), nominal public final consumption expenditure (US Dollar) and nominal private final consumption expenditure (US Dollar) can be treated as trend-stationary processes in both models. Lastly, the empirical findings are mixed in the case of Philippines and Singapore irrespective of whether the currency terms or the one-break and two-break models. For Philippines, nominal public final consumption expenditure and nominal private final consumption expenditure under local currency terms in two-break models versus US Dollar denomination nominal public final consumption expenditure and nominal private final consumption expenditure in one-break model are trend-stationary. However, the empirical findings in Singapore are considerably weak as most series can reject the null hypothesis of a unit root at 10 percent level. These include nominal gross domestic product and nominal private final consumption expenditure expressed in local currency as well as nominal public final consumption expenditure (US Dollar) two-break models whereas exports of goods (Local Currency) in one break models.

Overall, the ADF unit root test indicates that the ASEAN macroeconomic time series contain a unit root, while different endogenous break ADF-type unit root tests suggest that the time series are characterized as trend-stationary when breaks are considered.

The structural break dates are obviously different in terms of variables and countries. In this section, we focus on the break points which give the most negative results in the unit root hypothesis. Models LP and ZA suggest almost identical break points. In most series, the break points in ZA models suggest the same break date, which is also the first break or second break point in models LP. Nevertheless, there is a significant difference in the location of break dates between countries for each macroeconomic time series. Some of the break dates are closely connected with global events which have an influence on ASEAN macroeconomic fluctuations. To name a few [4], [18] have identified the location of break points coincide with the Great Depression, World War I, World War II and the energy shock periods. Moreover, [10] found that the structural breaks are associated with global economic depression in 2000-2002 for 26 of the 32 developed countries as well as 21 of the 26 developing countries. In this study, we find some common breaks in each series regardless of the one-break or two-break models. Generally, the break dates in model ZA and model LP are 
basically coincide with the first and second oil crisis in 1973 and 1979 , respectively, the commodity crisis in 1985-1986 as well as the second oil crisis of the Asian financial crisis in 1997-1998.

\section{CONCLUSION}

The objective of this study is to provide a comprehensive examination of the unit root hypothesis and structural breaks of 10 macroeconomic time series in ASEAN countries covering the period of 1960 - 2010, using different endogenous structural break ADF-type unit root tests. Our empirical findings guide to several important conclusions. First, using the ADF unit root tests, the evidence are more favorable for the unit root null regardless of whether the model includes the time trend. Second, by controlling the one-break and two-break in the models [16]-[18], we find that number of rejections of a unit root null is relatively higher than without considering breaks in the models. Macroeconomic time series under US Dollar and local currency terms have an opposite findings. As in ZA models, the US Dollar terms denomination series are more favorable of trend-stationary processes. Alternatively, the series that expressed in local currency terms tend to reject the null hypothesis of a unit root for all ASEAN countries except Thailand macroeconomic time series in LP models. Hence, the shocks to macroeconomic time series are temporary, these series will return to their long run trend rate of growth. Third, the common structural break dates occur among the ASEAN macroeconomic time series are closely associated with global economic events such as the first oil shock of 1973-1975, the second oil shock in 1979-1980, the commodity crisis in 1985-1986 and the Asian financial crisis of 1997-1998.

\section{POLICY IMPLiCATIONS}

In this study, several important policy implications are derived from the empirical findings. Firstly, the trend-stationary macroeconomic time series suggest that structural breaks should be taking into account in the models.

Secondly, if the shocks to series are transitory, then the macroeconomic stabilization policies may not be over-implemented in ASEAN countries particularly in Indonesia. Thirdly, more supportive evidence is found in line with trend-stationary processes for the rest of ASEAN macroeconomic time series denominated in the local currency for two-break specifications. Thus, our findings shed light on the importance of considering exchange rate fluctuations in testing unit root hypothesis and structural breaks.

\section{APPENDIX}

Another subsequent framework that considers for the possibility of single endogenous break in literature is [17]. Reference [17] provided a more comprehensive model to estimate the break point endogenously as compared to ZA The power of tests for both models are almost the same and the difference is only [17] models include both $t$ and
$D\left(T_{B}\right)$ while ZA models include $t$ only. Reference [17] models can be divided to 'innovational outlier (IO1 and IO2) models' and 'additive outlier (AO) model'. The IO models assume that the change is occurred gradually over time. More specifically, IO1 and IO2 allow one time change in the intercept and one time change in both intercept and slope, respectively $\mathrm{On}$ the contrary, $\mathrm{AO}$ model allows the change to occur rapidly, meaning that one time change in the slope.

\begin{tabular}{|c|c|c|c|c|c|c|}
\hline & \multirow[b]{2}{*}{ Variables } & \multicolumn{5}{|c|}{ IDN } \\
\hline & & Model & $\mathbf{K}$ & TB & $t$-statistic & \\
\hline 1 & LNGDP & IO2 & 0 & 1969 & -4.7612 & \\
\hline 2 & LNGDPUS & $\mathrm{IO} 2$ & 0 & 1997 & -3.0299 & \\
\hline 3 & LNPCE & $\mathrm{IO} 2$ & 7 & 1977 & -3.7152 & \\
\hline 4 & LNPCEUS & $\mathrm{IO} 2$ & 0 & 1997 & -2.7878 & \\
\hline 5 & LNPICE & $\mathrm{AO}$ & 0 & 1969 & -4.9256 & $* *$ \\
\hline 6 & LNPICEUS & $\mathrm{IO} 2$ & 0 & 1997 & -3.1186 & \\
\hline 7 & LX & $\mathrm{AO}$ & 0 & 1978 & -3.1859 & \\
\hline 8 & LXUS & IO1 & 0 & 1972 & -6.4459 & $* * *$ \\
\hline 9 & LM & $\mathrm{IO} 2$ & 0 & 1983 & -4.4243 & \\
\hline \multirow[t]{3}{*}{10} & LMUS & IO1 & 0 & 1972 & -4.1220 & \\
\hline & & \multicolumn{5}{|c|}{ MYS } \\
\hline & Variables & Model & $\mathbf{K}$ & TB & $t$-statistic & \\
\hline 1 & LNGDP & $\mathrm{IO} 2$ & 0 & 1972 & -3.5989 & \\
\hline 2 & LNGDPUS & IO1 & 0 & 1972 & -4.0276 & \\
\hline 3 & LNPCE & $\mathrm{IO} 2$ & 0 & 1984 & -3.2841 & \\
\hline 4 & LNPCEUS & IO1 & 0 & 1971 & -3.4208 & \\
\hline 5 & LNPICE & $\mathrm{IO} 2$ & 1 & 1976 & -4.1574 & \\
\hline 6 & LNPICEUS & IO1 & 1 & 1997 & -4.0705 & \\
\hline 7 & LX & $\mathrm{AO}$ & 0 & 2002 & -3.8285 & \\
\hline 8 & LXUS & IO1 & 0 & 1972 & -4.2960 & \\
\hline 9 & LM & $\mathrm{IO} 2$ & 0 & 1988 & -3.0664 & \\
\hline \multirow[t]{3}{*}{10} & LMUS & $\mathrm{IO} 2$ & 0 & 1988 & -3.0243 & \\
\hline & & \multicolumn{5}{|c|}{ PHL } \\
\hline & Variables & Model & $\mathbf{K}$ & TB & $t$-statistic & \\
\hline 1 & LNGDP & $\mathrm{IO} 2$ & 0 & 1983 & -3.4918 & \\
\hline 2 & LNGDPUS & $\mathrm{IO} 2$ & 8 & 1989 & -5.8849 & $* *$ \\
\hline 3 & LNPCE & $\mathrm{IO} 2$ & 0 & 1993 & -3.1059 & \\
\hline 4 & LNPCEUS & $\mathrm{IO} 2$ & 8 & 1993 & -5.9909 & $* *$ \\
\hline 5 & LNPICE & $\mathrm{IO} 2$ & 0 & 1983 & -4.3104 & \\
\hline 6 & LNPICEUS & $\mathrm{IO} 2$ & 8 & 1990 & -6.0701 & $* *$ \\
\hline 7 & LX & $\mathrm{IO} 2$ & 0 & 1997 & -4.7000 & \\
\hline 8 & LXUS & IO1 & 7 & 1977 & -3.3708 & \\
\hline 9 & LM & $\mathrm{AO}$ & 0 & 2002 & -3.3183 & \\
\hline \multirow[t]{3}{*}{10} & LMUS & IO1 & 1 & 1973 & -4.1090 & \\
\hline & & \multicolumn{5}{|c|}{ SGP } \\
\hline & Variables & Model & $\mathbf{K}$ & TB & $t$-statistic & \\
\hline 1 & LNGDP & IO2 & 1 & 1985 & -3.7120 & \\
\hline 2 & LNGDPUS & IO1 & 1 & 1997 & -4.0287 & \\
\hline 3 & LNPCE & $\mathrm{IO} 2$ & 0 & 1979 & -3.7396 & \\
\hline 4 & LNPCEUS & $\mathrm{IO} 2$ & 0 & 1979 & -3.2718 & \\
\hline 5 & LNPICE & $\mathrm{IO} 2$ & 3 & 1991 & -3.9592 & \\
\hline 6 & LNPICEUS & IO1 & 1 & 1997 & -3.8151 & \\
\hline 7 & LX & IO1 & 0 & 1972 & -4.5535 & \\
\hline 8 & LXUS & IO1 & 0 & 1972 & -4.3306 & \\
\hline 9 & LM & IO1 & 0 & 1972 & -3.9954 & \\
\hline \multirow[t]{3}{*}{10} & LMUS & IO1 & 0 & 1972 & -3.9060 & \\
\hline & & \multicolumn{5}{|c|}{ THA } \\
\hline & Variables & Model & $\mathbf{K}$ & TB & $t$-statistic & \\
\hline 1 & LNGDP & $\mathrm{IO} 2$ & 1 & 1997 & -3.9896 & \\
\hline 2 & LNGDPUS & IO1 & 1 & 1996 & -6.0413 & $* * *$ \\
\hline 3 & LNPCE & $\mathrm{IO} 2$ & 0 & 1977 & -3.5910 & \\
\hline 4 & LNPCEUS & IO1 & 1 & 1996 & -4.9769 & $*$ \\
\hline 5 & LNPICE & $\mathrm{IO} 2$ & 1 & 1991 & -3.4286 & \\
\hline 6 & LNPICEUS & IO1 & 1 & 1996 & -5.5304 & $* *$ \\
\hline 7 & LX & $\mathrm{AO}$ & 0 & 2000 & -2.9541 & \\
\hline 8 & LXUS & $\mathrm{IO} 2$ & 0 & 1972 & -2.9840 & \\
\hline 9 & LM & $\mathrm{IO} 2$ & 0 & 1986 & -3.8916 & \\
\hline 10 & LMUS & IO1 & 0 & 1996 & -3.9456 & \\
\hline
\end{tabular}

The optimal lag length is selected using $t$-sig approach as suggested by [31] with the maximum lag set to 8 . The [17] tests are based on the null hypothesis of unit root. $* * *, * *$, and $*$ indicate significant at 1 percent, 5 percent, and 10 
percent level respectively. The 1 percent, 5 percent and 10 percent asymptotic critical values for Model IO1: $-5.62,-5.23$ and -4.92 ; Model IO2 : $-6.32,-5.59$ and -5.29 ; Model AO : $-5.45,-4.83$ and -4.48

The results for [17] are presented in Table V. From these results, Indonesia, Malaysia, Philippines and Thailand would prefer model IO2, while Singapore in favor of model IO1. Allowing an endogenous break, less evidence is found against the unit root hypothesis than [16]. Macroeconomic time series in Philippines and Thailand show stronger support of trend-stationary processes than the rest of three ASEAN countries, rejecting the unit root null for three $(30.0 \%)$ out of 10 series at $5 \%$ level of significance or higher. It is then followed by the unit root null for two variables $(20.0 \%)$ in Indonesia. More interestingly, none of the macroeconomic variables can reject the hypothesis of a unit root in the case of Malaysia and Singapore. On the one hand, those macroeconomic variables being denominated in US dollar terms tend to be described as trend-stationary especially in Philippines and Thailand than local currencies-denominated variables.

\section{REFERENCES}

[1] C. R. Nelson and C. R. Plosser, "Trends and random walks in macroeconmic time series. Some evidence and implications," Journal of Monetary Economics, vol. 10, pp. 139-162, 1982.

[2] P. Arestis and I. B. F. Mariscal, "OECD unemployment: structural breaks and stationarity," Applied Economics, vol. 32, pp. 399-403, 2000 .

[3] S. A. Basher and J. Westerlund, "Is there really a unit root in the inflation rate? More evidence from panel data models," Applied Economics Letters, vol. 15, pp. 161-164, 2008.

[4] L. C. Chiang and C. C. Ping, "Trend stationary of inflation rates: evidence from LM unit root testing with a long span of historical data,' Applied Economics, vol. 40, pp. 2523-2536, 2008.

[5] C. C. Lee and J. D. Lee, "Energy prices, multiple structural breaks, and efficient market hypothesis," Applied Energy, vol. 86, pp. 466-479, 2009.

[6] P. K. Narayan and R. Smyth, "Are OECD stock prices characterized by a random walk? Evidence from sequential trend break and panel data models," Applied Financial Economics, vol. 15, pp. 547-556, 2005.

[7] P. Arestis and I. B. F. Mariscal, "Unit roots and structural breaks in OECD unemployment," Economics Letters, vol. 65, pp. 149-156, 1999.

[8] D. R. Ávila and C. Usabiaga, "The hypothesis of a unit root in OECD inflation revisited," Journal of Economics and Business, vol. 61, pp. 153-161, 2009.

[9] K. Chaudhuri and Y. Wu, "Random walk versus breaking trend in stock prices: Evidence from emerging markets," Journal of Banking and Finance, vol. 27, pp. 575-592, 2003.

[10] C. C. Lee et al., "Stock prices and the efficient market hypothesis: Evidence from a panel stationary test with structural breaks," Japan and the World Economy, vol. 22, pp. 49-58, 2010.

[11] P. K. Narayan and R. Smyth, "Mean reversion versus random walk in G7 stock prices evidence from multiple trend break unit root tests," Journal of International Financial Markets, Institutions and Money, vol. 17, pp. 152-166, 2007.

[12] N. Apergis and J. E. Payne, "Structural breaks and petroleum consumption in US states: Are shocks transitory or permanent?" Energy Policy, vol. 38, pp. 6375-6378, 2010.

[13] P. Newbold et al., "Trend-stationarity, difference-stationarity, or neither: further diagnostic tests with an application to U.S. Real GNP, 1875-1993," Journal of Economics and Business, vol. 53, pp. 85-102, 2001.

[14] A. Sen, "Are US macroeconomic series difference stationary or trend-break stationary?" Applied Economics, vol. 36, pp. 2025-2029, 2004.

[15] P. Perron, "The Great Crash, the oil price shock, and the unit root hypothesis," Econometrica, vol. 57, pp. 1361, 1989.

[16] E. Zivot and D. W. K. Andrews, "Further Evidence on the Great Crash, the Oil-Price Shock, and the Unit-Root Hypothesis," Journal of Business \& Economic Statistics, vol. 10, pp. 251-270, 1992.
[17] P. Perron, "Further evidence on breaking trend functions in macroeconomic variables," Journal of Econometrics, vol. 80, pp. 355-385, 1997.

[18] R. L. Lumsdaine and D. H. Papell, "Multiple trend breaks and the unit-root hypothesis," Review of Economics and Statistics, vol. 79, pp. 212-218, 1997.

[19] B. T. Ewing and P. V. Wunnava, "Unit roots and structural breaks in North American unemployment rates," North American Journal of Economics \& Finance, vol. 12, pp. 273, 2001.

[20] Y. Georgellis, "The oil price shocks and the unit root hypothesis: The UK experience," Applied Economics, vol. 26, pp. 827, 1994.

[21] B. Felmingham and L. Su San, "The stationarity of Australian real interest rates with and without structural breaks," Applied Economics Letters, vol. 10, pp. 239, 2003.

[22] A. Luísa, G. Abras et al., "Breaking trend, Lagrange multiplier test statistic and the presence of a unit root in the Brazilian gross domestic product," Applied Economics Letters, vol. 11, pp. 361-364, 2004.

[23] S. Narayan and R. Smyth, "Unit roots and structural breaks in PNG macroeconomic time series," International Journal of Social Economics, vol. 35, pp. 963-984, 2008.

[24] R. Smyth and B. Inder, "Is Chinese provincial real GDP per capita nonstationary? Evidence from multiple trend break unit root tests,' China Economic Review (1043951X), vol. 15, pp. 1, 2004.

[25] W. W. Charemza et al., "Is inflation stationary?" Applied Economics, vol. 37, pp. 901-903, 2005.

[26] A. Mehl, "Unit root tests with double trend breaks and the 1990s recession in Japan," Japan and the World Economy, vol. 12, pp. 363-379, 2000.

[27] H. C. Bjornland, "Structural breaks and stochastic trends in macroeconomic variables in Norway," Applied Economics Letters, vol. 6, pp. 133-138, 1999.

[28] D. A. Dickey and W. A. Fuller, "Distribution of the estimators for autoregressive time series with a unit root," Journal of the American Statistical Association, vol. 74, pp. 427-431, 1979.

[29] D. A. Dickey and W. A. Fuller, "Likelihood ratio statistics for autoregressive time series with a unit root," Econometrica: Journal of the Econometric Society, pp. 1057-1072, 1981.

[30] A. Hall, "Testing for a Unit Root in Time Series With Pretest Data-Based Model Selection," Journal of Business \& Economic Statistics, vol. 12, pp. 461-470, 1994.

[31] S. Ng and P. Perron, "Unit Root Tests in ARMA Models with Data-Dependent Methods for the Selection of the Truncation Lag," Journal of the American Statistical Association, vol. 90, pp. 268-281, 1995.

[32] P. K. Narayan and R. Smyth, "Structural breaks and unit roots in Australian macroeconomic time series," Pacific Economic Review, vol. 10, pp. 421-437, 2005.

[33] P. Perron and T. J. Vogelsang, "Nonstationarity and Level Shifts With an Application to Purchasing Power Parity," Journal of Business \& Economic Statistics, vol. 10, pp. 301-320, 1992.

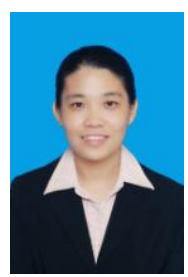

Tan Yan Ling was born in Muar, Johor. Currently pursuing her Ph.D. studies in Economics (ongoing), Universiti Putra Malaysia, Serdang, Selangor, Malaysia, graduated with master (Econs.) (2007) and bachelor (Econs.) (2002). Both degrees are from Universiti Kebangsaan Malaysia. Currently she is on study leave from Faculty of Business and Management, Universiti Teknologi MARA Johor Branch, Segamat, Johor, Malaysia.

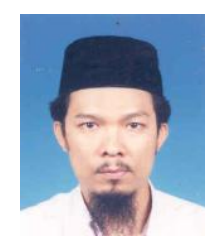

Abu Hassan Shaari Mohd Nor was born in Por Dickson, Negeri Sembilan. He obtained his Ph.D. in Statistics, from Okhlahoma State University, USA 1989. He graduated in 1981 with MSc (Statistics) from Iowa University, USA. He graduated his BSc (Mathematics) from Southern Illinois University, USA in 1979. Currently, he is a professor, at School of Economics, Faculty of Economics and Management, Universiti Kebangsaan Malaysia, Bangi, Selangor, Malaysia. He has extensive experience in Advanced Econometrics, Econometrics Time Series, Research Methodology, Statistical Methods and Data Analysis, Analysis and Design of Experiments and Statistical Inference. 


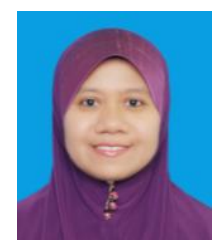

Nur Adilah Saud was born in Segamat, Johor Currently pursuing her Ph.D. studies in Marketing (ongoing), Universiti Putra Malaysia, Serdang, Selangor, Malaysia. She graduated with MBA (2004) from Universiti Kebangsaan Malaysia and BBA (Marketing) (Hons.) (2002) from Universiti Teknologi MARA. Currently she is on study leave from Faculty of Business and Management, Universiti Teknologi MARA Johor Branch, Segamat, Johor, Malaysia

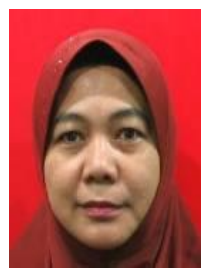

Zailati Ahmad was born in Pekan, Pahang. She graduated with Master of Science (Human Resource Development) (2003) from Universiti Teknologi Malaysia, Skudai, Johor, Malaysia and bachelor of Economics (Hons.) Analytical (1988) from University of Malaya, Kuala Lumpur, Malaysia. Currently she is a senior lecturer at Faculty of Business and Management, Universiti Teknologi MARA Johor Branch, Segamat, Johor, Malaysia. 